\title{
Long-term Outcome and Late Side Effects in Endometrial Cancer Patients Treated with Surgery and Postoperative Radiation Therapy
}

\author{
Fernanda G. Herrera, MD ${ }^{1}$, Olalla Santa Cruz, $\mathbf{M D}^{1}$, Chahin Achtari, $\mathrm{MD}^{2}$, Jean Bourhis, $\mathbf{M D}^{1}$, and \\ Mahmut Ozsahin, MD, PhD ${ }^{1}$ \\ ${ }^{1}$ Department of Radiation Oncology, Centre Hospitalier Universitaire Vaudois (CHUV), Lausanne, Switzerland; \\ ${ }^{2}$ Department of Gynecology Oncology, Centre Hospitalier Universitaire Vaudois (CHUV), Lausanne, Switzerland
}

\begin{abstract}
Background. We retrospectively reviewed the long-term outcome and late side effects of endometrial cancer (EC) patients treated with different techniques of postoperative radiotherapy (PORT).

Methods. Between 1999 and 2012, 237 patients with EC were treated with PORT. Two-dimensional external beam radiotherapy (2D-EBRT) was used in 69 patients (30\%), three-dimensional EBRT (3D-EBRT) in $51(21 \%)$, and intensity-modulated RT (IMRT) with helical Tomotherapy in $47(20 \%)$. All patients received a vaginal brachytherapy (VB) boost. Seventy patients (29\%) received VB alone.

Results. After a median of 68 months (range, 6-154) of follow-up, overall survival was $75 \%$ [95\% confidence interval (CI), 69-81], disease-free survival was $72 \%(95 \%$ CI, 66-78), cancer-specific survival was $85 \%$ (95\% CI, 80-89), and locoregional control was $86 \%$ (95\% CI, $81-91)$. The 5 -year estimates of grade 3 or more toxicity and second cancer rates were 0 and $7 \%$ (95\% CI, 1-13) for $\mathrm{VB}$ alone, $6 \%(95 \% \mathrm{CI}, 1-11)$ and $0 \%$ for IMRT + VB, $9 \%(95 \% \mathrm{CI}, 1-17)$ and $5 \%(95 \% \mathrm{CI}$, 1-9) for 3D-EBRT + VB, and $22 \%$ (95\% CI, 12-32) and $12 \%(95 \% \mathrm{CI}, 4-20)$ for $2 \mathrm{D}-\mathrm{EBRT}+\mathrm{VB}(P=0.002$ and $P=0.01$ ), respectively.

Conclusions. Pelvic EBRT should be tailored to patients with high-risk EC because the severe late toxicity observed might outweigh the benefits. When EBRT is prescribed for
\end{abstract}

(C) Society of Surgical Oncology 2014

First Received: 3 January 2014;

Published Online: 7 March 2014

M. Ozsahin, $\mathrm{MD}, \mathrm{PhD}$

e-mail: esat-mahmut.ozsahin@chuv.ch
EC, IMRT should be considered, because it was associated with a significant reduction of severe late side effects.

Endometrial cancer (EC) is the most common gynecologic malignancy in developed countries. ${ }^{1,2}$ At the time of diagnosis, most patients present with early-stage disease, and low-risk patients have a risk of locoregional recurrence (LRR) of 5-10\%. However, high- to intermediate-risk patients harbor a combination of high-grade, deep myometrial invasion and/or lymphovascular space invasion (LVSI), with a risk of LRR of up to $27 \%{ }^{3}$ Randomized studies have shown that postoperative radiotherapy (PORT) decreases the LRR rate without affecting overall survival (OS). However, two-thirds of the patients in those trials had low-risk disease and a substantial risk of dying as a result of competing hazards. ${ }^{3-8}$ The long-term outcome of these trials also confirmed the morbidity risks of adjuvant PORT using mainly two-dimensional (2D) external beam radiotherapy (EBRT) techniques. ${ }^{9}$ The postoperative radiotherapy in EC (PORTEC-2) randomized trial showed that the toxicity of PORT using three-dimensional (3D)EBRT techniques outweighs the benefits and that vaginal brachytherapy (VB) alone can be enough to avoid local recurrences in the subgroup of patients with high- to intermediate-risk factors (grade 1-2 tumors, $>50 \%$ myometrial invasion, endometrioid type, age $>60$ years, and no LVSI). ${ }^{10}$ Pelvic radiotherapy (RT) has changed dramatically over the last few decades with the introduction of intensity-modulated RT (IMRT). The question that remains open is whether IMRT will lead to a reduced rate of severe side effects. Studies have found evidence of an increased risk of secondary neoplasms after PORT, and some investigators have recently postulated that IMRT can potentially increase the risk of second cancers..$^{9,11,12} \mathrm{We}$ 
aimed in this study to assess a population-based cohort who received adjuvant PORT over a 12 -year period with different technique of RT. In our series, IMRT was delivered with helical Tomotherapy (Accuray, Madison, WI). Tomotherapy is a new generation 6-MV photon accelerator that allows helical delivery of highly conformal and homogeneous doses associated with daily image-guided RT. We assessed the severe late toxicity (grade 3 or more) and the incidence of second cancers.

\section{METHODS}

\section{Study Population}

After approval by the local ethics committee, we retrospectively reviewed the charts of 237 eligible patients from a total of 245 EC patients who received adjuvant PORT between 1999 and 2012 at the Lausanne University Hospital. Inclusion criteria were a pathologic diagnosis of EC, stage I-IVA according to the International Federation of Gynecology and Obstetrics (FIGO) 1988 definition, and a minimum of 6 months of follow-up. ${ }^{13}$ One patient was excluded from the analysis because of disseminated disease, and 7 patients were excluded for incomplete followup. Data were obtained from the electronic and written medical records and included age at diagnosis, date of diagnosis, date of surgery, type of surgical procedure, number of pathologically examined lymph nodes, surgical margins, histology, grade, depth of myometrial invasion, stage, LVSI, type and dose of PORT, date and location of recurrence, date of last follow-up, date of death, incidence and types of second cancers, and late side effects (grade 3 or more) based on common terminology criteria for adverse events version 4.0, which were confirmed from follow-up records and surgical and/or procedural interventions. Sites of failure were grouped into isolated vaginal recurrence, LRR (pelvic and/or paraaortic), and distant metastases (extraabdominal sites and positive peritoneal cytology).

\section{Statistical Considerations}

Proportions were compared by using the Chi square test for values of 5 or higher and with Fisher's exact test for values of less than 5 . Survival curves were estimated by using the Kaplan-Meier method. Time to any event was measured from the day RT started. Death certificates confirmed date of deaths. If clinical or pathologic evidence of active, recurrent disease was present, deaths were attributed to EC. The events were death (all causes) for OS, EC-related mortality for cancer-specific survival (CSS), and death (all causes) or relapse for disease-free survival
(DFS). For the locoregional control (LRC) rate, the event consisted of local or regional relapse. Confidence intervals (CI) were calculated from standard errors. In univariate analyses, differences between groups were assessed by using the log-rank test. All obtained significant $P$ values were corrected for multiple comparisons with the Bonferroni correction method in which the $P$ values are multiplied by the number of comparisons. In multivariate analyses, we screened for prognostic factors with a $P$ value of less than 0.05 in univariate analyses by using the Cox regression analysis to define the independent contribution of each prognostic factor. A $P$ value of $<0.05$ was considered to be statistically significant. All data were examined using JMP version 9.0.1 (SAS Institute Inc., Cary, NC).

\section{RESULTS}

\section{Patient Characteristics}

A total of 237 patients with EC were identified with complete follow-up. Patients' surgical, pathologic, and treatment characteristics are detailed in Table 1. The median age was 69 years (range, 37-90 years).

\section{Surgery}

All patients underwent total abdominal hysterectomy and bilateral salpingo-oophorectomy (TAH-BSO) including abdominal washing, with $(n=126)$ or without ( $n=111)$ lymphadenectomy.

\section{Radiotherapy}

RT started 6-8 weeks after surgery and was delivered by using a two-dimensional four-field technique (2D-EBRT) in 69 patients (30\%), four-field conformal RT (3D-EBRT) in $51(21 \%)$, and Tomotherapy in $47(20 \%)$. All of the patients treated in the Tomotherapy group had daily image-guided RT using helical megavoltage-based computed tomography. All patients treated with different techniques of EBRT also received a VB boost. Seventy patients $(29 \%)$ were treated with postoperative VB alone. Patients treated with 2D-EBRT had the radiation portals determined using a kilovoltage simulator. From the introduction of 3D-EBRT, target volumes and organs at risk were contoured on a computed tomography image, and personalized shielding was applied by using the multileaf collimator. For both 2D-EBRT and 3D-EBRT, the radiation fields extended from the anterior aspect of the pubic symphysis to the L5-S1 interspace and laterally posteriorly up to the middle sacrum. With the introduction of helical Tomotherapy, the radiation volumes were based on the 
radiation therapy oncology group consensus guidelines, including the irradiation of common iliac nodes. ${ }^{14}$ The median EBRT dose was 45 Gy (range, 41.4-50.4 Gy) in fractions of $1.8 \mathrm{~Gy}$. VB was administered to the upper $3 \mathrm{~cm}$ of the vagina by using a high-dose rate technique delivered via vaginal cylinders; the dose was prescribed to the vaginal mucosa $(0.5 \mathrm{~cm}$ from the cylinder surface). The median number of VB fractions was 3 (range, 2-6), and the median VB dose was 5 Gy per fraction (range, 3-7.5 Gy). The most frequent VB regimen was $10 \mathrm{~Gy}$ in 2 fractions for those previously receiving EBRT (VB boost) and $20 \mathrm{~Gy}$ in 4 fractions for those only receiving VB.

\section{Disease Outcome}

In a median follow-up of 68 months (range, 6-154 months), the 5-year OS was $75 \%$ (95\% CI, 69-81), DFS was $72 \%$ (95\% CI, 66-78), CSS was $85 \%(95 \%$ CI, 80-89), and LRC was $86 \%$ (95\% CI, 81-91). By the end of follow-up, 161 of 237 (68\%) patients were alive without disease, and 12 of 237 were alive with recurrent disease. Thirty-three of 237 (14\%) patients died of EC, and 31 of $237(13 \%)$ died of intercurrent diseases (24 cardiovascular, $6 \mathrm{~s}$ tumors, and 1 treatment-related toxicity). A total of 47 patients $(20 \%)$ experienced a recurrence. In univariate analyses, statistically significant factors unfavorably influencing OS and DFS were patient age ( $>69$ years), presence of LVSI, advanced stage, papillary-serous or clear-cell histology, grade 3 tumors, absence of lymphadenectomy, presence of positive lymph nodes, and positive abdominal washing. For CSS and LRC, the previously mentioned parameters applied, except for age (Table 2). After multivariate analyses, the remaining independent prognostic factors unfavorably influencing OS and DFS were age ( $>69$ years), advanced stage, positive LVSI, absence of lymphadenectomy, and grade 3 histology. For CSS and LRC, the previously mentioned variables applied except for age (Table 3).

The 5-year LRC rate was $89 \%$ (95\% CI, 80-96) for patients treated with VB alone versus $85 \%(95 \% \mathrm{CI}$, 79-91) for those treated with EBRT + VB $(P=0.5)$. Among those treated with VB alone, there was an increased proportion of patients with endometrioid-type histology [endometrioid type $(n=62)$ versus serous type or clear cell $(n=8) ; P=0.0026]$, grade $1-2$ [grade $1-2(n=67)$ versus grade $3(n=3), P<0.0001]$, earlier-stage tumors [Ia, b, and IIa $(n=23)$, Ic $(n=42)$, and IIb $(n=5)$; $P<0.0001$ ], and absence of LVSI [LVSI absent $(n=64)$, LVSI present $(n=6) ; P<0.0001]$. When comparing patients $(n=60)$ who fit the PORTEC- 2 inclusion criteria, i.e., stage I tumors, patients $>60$ years old (Ic and grade 1 or 2 ), or Ib (grade 3 ) or stage IIa tumors at any age excluding grade 3 or $>50 \%$ myometrial invasion, with
TABLE 1 Patients' surgical, pathologic, and treatment characteristics $(n=237)$

\begin{tabular}{|c|c|c|}
\hline Characteristic & $n$ & $\%$ \\
\hline \multicolumn{3}{|l|}{1988 FIGO stage } \\
\hline Ia & 5 & 2 \\
\hline $\mathrm{Ib}$ & 54 & 22.7 \\
\hline Ic & 75 & 31.6 \\
\hline IIa & 16 & 6.7 \\
\hline IIb & 46 & 19.4 \\
\hline IIIa & 6 & 2.5 \\
\hline IIIb & 2 & 0.8 \\
\hline IIII & 30 & 12.6 \\
\hline IVa & 1 & 0.4 \\
\hline \multicolumn{3}{|l|}{ LVSI } \\
\hline Positive & 77 & 32.5 \\
\hline Negative & 160 & 67.5 \\
\hline \multicolumn{3}{|l|}{ Grade } \\
\hline $1-2$ & 169 & 71.3 \\
\hline 3 & 68 & 28.6 \\
\hline \multicolumn{3}{|l|}{ Histology } \\
\hline Clear cell/serous papillary & 56 & 23.6 \\
\hline Endometrial type & 181 & 76.3 \\
\hline \multicolumn{3}{|l|}{ Pelvic lymphadenectomy } \\
\hline Performed & 126 & 53 \\
\hline Not performed & 111 & 47 \\
\hline \multicolumn{3}{|l|}{ Paraaortic lymphadenectomy } \\
\hline Performed & 35 & 14.7 \\
\hline Not performed & 202 & 85.2 \\
\hline \multicolumn{3}{|l|}{ Radiotherapy technique } \\
\hline VB & 70 & 29.5 \\
\hline 2D-EBRT + VB & 69 & 29 \\
\hline 3D-EBRT + VB & 51 & 21.5 \\
\hline Tomotherapy + VB & 47 & 20 \\
\hline
\end{tabular}

FIGO international federation of gynecology and obstetrics staging system, LVSI lymphovascular space invasion, $V B$ vaginal cuff brachytherapy, $2 D-E B R T$ two-dimensional external beam radiotherapy, $3 D-E B R T$ three-dimensional external beam radiotherapy

those without the PORTEC-2 criteria $(n=177)$, the 5-year LRC was $96 \%$ (95\% CI, 91-100) versus $83 \%(95 \%$ CI, 77-89; $P=0.02)$, respectively. ${ }^{10}$

\section{Toxicity}

By the end of follow-up, 24 patients $(9.7 \%$ ) developed severe late toxicity (grade 3 or more). Two patients developed urethral stenosis requiring surgery, resulting in permanent urinary incontinence. Three patients developed synchronous urethral stenosis and rectovaginal fistulas. Sixteen patients had intestinal toxicity (bowel stenosis and/ or rectovaginal fistulas). One patient died because of small- 
TABLE 2 Univariate analysis

\begin{tabular}{|c|c|c|c|c|c|c|c|c|c|c|c|c|c|}
\hline Variable & $n$ & $\begin{array}{l}\text { 5-Year } \\
\text { OS }(\%)\end{array}$ & $\begin{array}{l}95 \% \\
\text { CI }\end{array}$ & $P$ value & $\begin{array}{l}\text { 5-Year } \\
\text { DFS (\%) }\end{array}$ & $\begin{array}{l}95 \% \\
\text { CI }\end{array}$ & $P$ value & $\begin{array}{l}\text { 5-Year } \\
\text { CSS }(\%)\end{array}$ & $\begin{array}{l}95 \% \\
\mathrm{CI}\end{array}$ & $P$ value & $\begin{array}{l}5-Y e a r \\
\text { LRC }(\%)\end{array}$ & $\begin{array}{l}95 \% \\
\mathrm{CI}\end{array}$ & $P$ value \\
\hline All patients & 237 & 75 & $69-81$ & & 72 & $66-78$ & & 85 & $80-89$ & & 86 & $81-91$ & \\
\hline \multicolumn{14}{|l|}{ Age (years) } \\
\hline$<69$ & 116 & 83 & $75-91$ & 0.0004 & 82 & $75-89$ & 0.0004 & 87 & $81-93$ & 0.25 & 88 & $82-94$ & 0.49 \\
\hline$>69$ & 121 & 68 & $59-77$ & $0.003^{\mathrm{a}}$ & 62 & $52-71$ & $0.003^{\mathrm{a}}$ & 82 & $75-89$ & & 85 & $78-92$ & \\
\hline \multicolumn{14}{|l|}{ LVSI } \\
\hline Negative & 160 & 82 & $76-88$ & 0.0004 & 78 & $71-85$ & $<0.0001$ & 88 & $82-93$ & 0.007 & 90 & $85-95$ & 0.002 \\
\hline Positive & 77 & 60 & $46-74$ & $0.003^{\mathrm{a}}$ & 54 & $41-67$ & $0.0008^{\mathrm{a}}$ & 77 & $67-87$ & $0.06^{\mathrm{a}}$ & 75 & $63-87$ & $0.02^{\mathrm{a}}$ \\
\hline \multicolumn{14}{|l|}{ FIGO stage } \\
\hline $\mathrm{Ia} / \mathrm{b} / \mathrm{IIA}$ & 75 & 86 & $78-94$ & & 82 & 73-91 & & 94 & 88-99 & & 94 & 89-99 & \\
\hline Ic & 75 & 78 & $67-89$ & 0.0013 & 75 & $67-73$ & 0.001 & 89 & $81-97$ & 0.0002 & 93 & 87-99 & 0.0001 \\
\hline IIb & 46 & 61 & $45-77$ & $0.01^{\mathrm{a}}$ & 62 & $47-77$ & $0.008^{\mathrm{a}}$ & 71 & $57-85$ & $0.002^{\mathrm{a}}$ & 74 & $64-84$ & $0.0008^{\circ}$ \\
\hline III & 41 & 54 & $37-81$ & & 58 & $41-75$ & & 63 & $45-87$ & & 60 & $50-70$ & \\
\hline \multicolumn{14}{|l|}{ Histology } \\
\hline Endometrioid & 181 & 77 & $70-84$ & 0.06 & 75 & $68-82$ & 0.01 & 88 & $83-93$ & 0.003 & 89 & 84-94 & 0.01 \\
\hline Clear cell/papillary & 56 & 69 & $55-82$ & & 61 & $48-74$ & $0.08^{\mathrm{a}}$ & 73 & $61-85$ & $0.02^{\mathrm{a}}$ & 79 & $67-91$ & $0.08^{\mathrm{a}}$ \\
\hline \multicolumn{14}{|l|}{ Grade } \\
\hline $1-2$ & 169 & 80 & $73-87$ & 0.0006 & 79 & $72-85$ & 0.0002 & 89 & 84-94 & 0.004 & 89 & 84-94 & 0.04 \\
\hline 3 & 68 & 63 & $50-76$ & $0.005^{\mathrm{a}}$ & 51 & $37-65$ & $0.002^{\mathrm{a}}$ & 73 & $60-86$ & $0.03^{\mathrm{a}}$ & 73 & $58-88$ & $0.32^{\mathrm{a}}$ \\
\hline \multicolumn{14}{|l|}{ Lymphadenectomy } \\
\hline Not performed & 111 & 69 & $60-78$ & 0.01 & 65 & $57-75$ & 0.03 & 75 & $65-82$ & 0.01 & 76 & $69-83$ & 0.04 \\
\hline Performed & 126 & 80 & $72-88$ & $0.08^{\mathrm{a}}$ & 78 & $70-86$ & $0.24^{\mathrm{a}}$ & 88 & $82-94$ & $0.08^{\mathrm{a}}$ & 86 & $80-92$ & $0.32^{\mathrm{a}}$ \\
\hline \multicolumn{14}{|l|}{ Lymph nodes } \\
\hline Positive & 28 & 57 & $55-59$ & 0.02 & 58 & $56-60$ & 0.005 & 71 & $53-89$ & 0.01 & 65 & $63-67$ & 0.0001 \\
\hline Negative & 209 & 77 & $71-83$ & $0.16^{\mathrm{a}}$ & 74 & $68-80$ & $0.04^{\mathrm{a}}$ & 86 & $81-91$ & $0.08^{\mathrm{a}}$ & 89 & 84-93 & $0.0008^{\circ}$ \\
\hline \multicolumn{14}{|l|}{ Washing } \\
\hline Negative & 222 & 77 & $71-83$ & 0.03 & 74 & $68-80$ & 0.009 & 86 & $81-91$ & 0.05 & 88 & 83-93 & 0.0029 \\
\hline Positive & 15 & 51 & $48-54$ & $0.24^{\mathrm{a}}$ & 45 & $42-48$ & $0.07^{\mathrm{a}}$ & 67 & $64-70$ & $0.4^{\mathrm{a}}$ & 65 & $62-68$ & $0.02^{\mathrm{a}}$ \\
\hline
\end{tabular}

LVSI lymphovascular space invasion, $O S$ overall survival, DFS disease-free survival, CSS cancer-specific survival, LRC locoregional control, $C I$ confidence interval, FIGO international federation of gynecology and obstetrics staging system

${ }^{a} P$ values after Bonferroni multiple correction analysis

TABLE 3 Multivariate Cox analysis

\begin{tabular}{|c|c|c|c|c|c|c|c|c|}
\hline \multirow[t]{2}{*}{ Variable } & \multicolumn{2}{|l|}{ OS } & \multicolumn{2}{|l|}{ DFS } & \multicolumn{2}{|l|}{ CSS } & \multicolumn{2}{|l|}{ LRC } \\
\hline & $\mathrm{RR}$ & $P$ value & $\mathrm{RR}$ & $P$ value & $\mathrm{RR}$ & $P$ value & $\mathrm{RR}$ & $P$ value \\
\hline Age $>69$ years & 1.04 & 0.0006 & 1.11 & 0.0003 & - & NS & - & NS \\
\hline \multicolumn{9}{|l|}{ Stage } \\
\hline $\begin{array}{l}\text { Ia/b/IIa vs. } \\
\text { Ic vs. IIb vs. III }\end{array}$ & 1.53 & 0.0001 & 1.99 & 0.001 & 1.03 & $<0.0001$ & 1.12 & 0.005 \\
\hline LVSI positive & 1.72 & 0.04 & 1.63 & 0.01 & 1.51 & 0.01 & 1.02 & 0.01 \\
\hline Lymphadenectomy (not performed) & 1.08 & 0.02 & 1.75 & 0.02 & 1.13 & 0.01 & 1.09 & 0.01 \\
\hline Grade 3 histology & 1.38 & 0.01 & 1.35 & 0.005 & 1.33 & 0.04 & 1.34 & 0.01 \\
\hline
\end{tabular}

LVSI lymphovascular space invasion, OS overall survival, DFS disease-free survival, CSS cancer-specific survival, LRC locoregional control, $N S$ nonsignificant, $R R$ relative risk 
bowel obstruction; she developed an acute abdomen requiring emergency surgery and died 1 week later. We registered two patients with severe chronic lymphedema, one of whom had severe intestinal toxicity requiring surgery. One patient had a radiation-induced sacral fracture. According to the RT technique, the 5-year Kaplan-Meier estimate of grade 3 or more toxicity was $0 \%$ for $\mathrm{VB}$ alone, $6 \%(95 \%$ CI, 1-11) for helical Tomotherapy + VB, $9 \%$ (95\% CI, 1-17) for 3D-EBRT + VB, and $22 \%(95 \% \mathrm{CI}$, 12-32) for 2D-EBRT + VB $(P=0.002$; Fig. 1$)$.

\section{Second Cancers}

In a follow-up period of 10-151 months, 24 patients (10\%) were diagnosed with second cancers after PORT. The 5- and 10-year estimated second-cancer incidence was $9 \%$ (95\% CI, 5-13) and $23 \%$ (95\% CI, 13-33), respectively, for the whole population. The 10-year estimated second-cancer rate was $19 \%$ (95\% CI, 10-29) in patients younger than 60 years at diagnosis versus $15 \%$ (95\% CI, 9-21) compared with those 60 years or more $(P=0.46)$. In 4 of 24 women, the malignancy was situated inside or in close proximity to the irradiated volume. The most common in-field second cancers were bladder $(n=1)$ and colorectal $(n=3)$ cancer. The most common out-offield malignancy was breast cancer $(n=12)$. According to the RT technique, the 5-year estimated second-cancer incidence was $0 \%$ for helical Tomotherapy, $5 \%$ for 3D-EBRT (95\% CI, 1-9), $7 \%$ for VB alone (95\% CI, $1-13)$, and $12 \%$ (95\% CI, 4-20) for 2D-EBRT $(P=0.01)$.

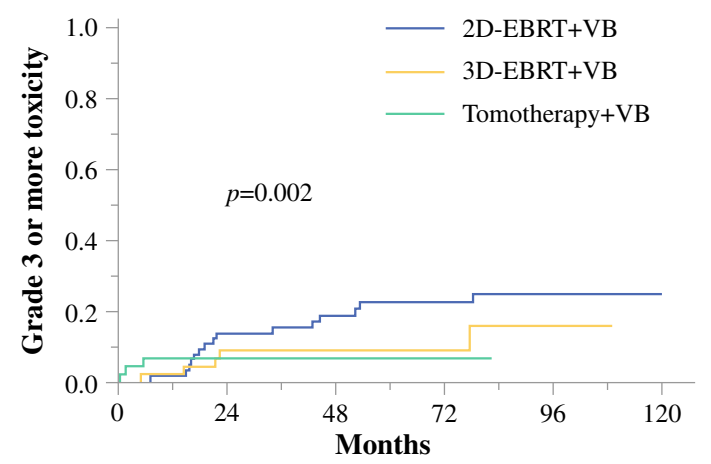

Number at risk

$\begin{array}{llllll}\text { 2D-EBRT+VB }(\mathrm{n}=69) & 58 & 46 & 34 & 24 & 13 \\ \text { 3D-EBRT+VB }(\mathrm{n}=51) & 41 & 25 & 16 & 3 & \\ \text { Tomotherapy+VB }(\mathrm{n}=43) & 32 & 6 & 2 & & \end{array}$

FIG. 1 Grade 3 or more late toxicity by radiotherapy technique. $2 D$ $E B R T$ two-dimensional external beam radiation therapy, $3 D-E B R T$ three-dimensional external beam radiation therapy, $V B$ vaginal cuff brachytherapy

\section{DISCUSSION}

It is recognized that EBRT in patients with EC leads to better pelvic control compared with surgery alone. A favorable influence on survival, however, has failed to be shown in several randomized trials and meta-analyses. ${ }^{3-6,8}$ Therefore, the life expectancy of these patients should be taken into consideration to tailor adjuvant RT with the final aim of keeping good LRC while preventing RT-related side effects. Depending on the treatment technique, prognostic factors, and median follow-up time, in early stage disease LRR rates are in the range of $5-15 \% .{ }^{15,16}$ Our results compare well with the literature (14\%; $95 \%$ CI, 9-19) and confirm good LRC with PORT (Table 4). Patients treated with VB alone had a 5-year LRC of $89 \%$. Wellselected high- to intermediate-risk patients according to the PORTEC-2 inclusion criteria had an LRC rate of $96 \%$ at 5 years. These results are in line with those obtained in PORTEC-2, suggesting the feasibility of such an approach in an appropriately selected subgroup of patients. ${ }^{10}$ It is important to note that in the PORTEC- 2 study, there was also a significant quality-of-life advantage for patients receiving VB alone. ${ }^{17}$ Serious complications in 3-5\% of patients after PORT have been reported in various randomized trials and, as in our patients, concerned mainly the gastrointestinal tract. ${ }^{3,4,6,9}$ In our study, severe complications were diagnosed in nearly $10 \%$ of the patients. These higher-than-expected rates of severe late complications are in line with what is reported in other studies using EBRT + VB. ${ }^{18}$ We agree that the benefit of VB as a boost after EBRT is questionable. ${ }^{19}$ The increased incidence of injury to the bowel might be explained by the fact that after hysterectomy, the small-bowel loops occupy the place of the uterus, thereby receiving high doses of EBRT and remaining close to the VB source. We have recently abandoned the systematic use of the VB boost, offering this additional treatment only to patients with cervical invasion or positive vaginal margins. In our series, we showed that the change from 2D- to 3D-EBRT and to helical Tomotherapy significantly decreased the incidence of severe side effects. The use of IMRT for gynecologic cancers is still a matter of debate. The largest prospective study comparing non-IMRT versus IMRT showed a reduction in grade 3 or more long-term toxicity from 17 to $6 \% .^{20}$ Other retrospective series comparing 3D-EBRT versus IMRT after TAH-BSO have failed to show any benefit. ${ }^{21} \mathrm{~A}$ recent phase II feasibility trial by the radiation therapy oncology group reported a nonsignificant $12 \%$ reduction in grade 2 or more bowel adverse events in patients treated with IMRT after TAH-BSO. ${ }^{22}$ A phase III randomized trial is warranted to confirm the potential benefits of IMRT in EC. In our series, the 5-year second-cancer incidence was $0 \%$ for helical Tomotherapy, $5 \%$ for 3D-EBRT, and $12 \%$ for 


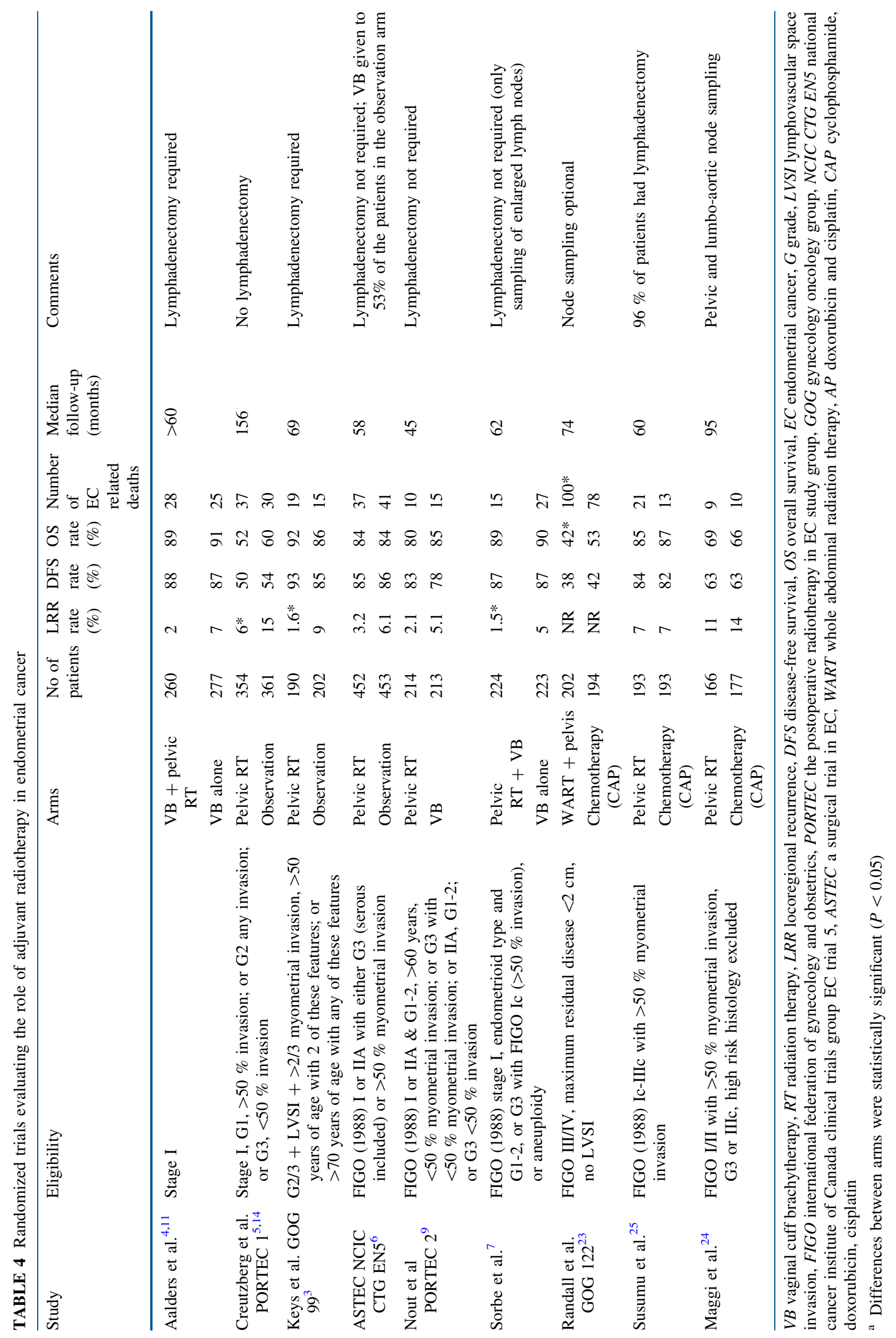


2D-EBRT, keeping in mind the shorter follow-up in Tomotherapy patients. Onsrud et al. ${ }^{11}$ analyzed the longterm outcome of a randomized trial of postoperative $\mathrm{VB}+$ EBRT versus VB alone. After a median follow-up of 20.5 years, women younger than 60 years treated with $\mathrm{VB}+$ EBRT had a significantly higher mortality rate due to second malignancies (hazard ratio, 2.02; $95 \% \mathrm{CI}$, 1.3-3.1). It should be noted that the RT delivery in that study was performed mainly with cobalt-60 using a twofield technique. This technique fully exposes the bladder and the bowel to high doses of radiation. The 15-year rates of second cancers in the PORTEC-1 randomized trial were $22 \%$ in patients treated with adjuvant EBRT versus $16 \%$ in the observational group $(P=0.10)$. The incidence rates were compared with those of an age-and sex-matched population. The observed versus expected ratios were 1.40 for the total group (1.62 for EBRT and 1.2 for the observational group, $P$ not significant). The predominant cancer types were gastrointestinal cancer $(6.2 \%$ in the EBRT group vs. $3.2 \%$ in the observational group) and breast cancer (4.8\% in the EBRT group vs. $6.6 \%$ in the observational group). These differences did not reach statistical significance. ${ }^{15}$ Chaturvedi et al. ${ }^{23}$ reported on a series of 101,760 cervical cancer patients with more than 40 years of follow-up who were treated $(n=52,613)$ or not treated ( $n=27,382$ ) with RT. They observed 12,496 incidents of second cancers [standard incidence ratio $(\mathrm{SIR})=1.30$, $95 \%$ CI, 1.28-1.33]. Compared with the general population, the excess absolute risk was 22.7 per 10,000 personyears. Cervical cancer patients treated with RT as opposed to those not treated with RT were at increased risk of second cancers at any site, and the SIR was dependent on the amount of RT administered. Heavily irradiated organs located in the irradiated field and receiving $>3$ Gy (average radiation dose was 10-66 Gy depending on the location of the organ) had an SIR of 1.59 (95\% CI, 1.16-1.26), compared with moderately (1-3 Gy) and lightly (<1 Gy) irradiated sites $(\mathrm{SIR}=1.30,95 \% \mathrm{CI}, 1.54-1.66$, and $\mathrm{SIR}=1.21,95 \% \mathrm{CI}, 1.16-1.26$, respectively). This study demonstrates that the risk of RT-induced second cancers increases with time and that there is an RT dose effect.

Our study adds information to the ongoing discussion in prescribing adjuvant EBRT versus VB and the technology of EBRT. Nevertheless, because of its retrospective approach, it has several limitations. We could not obtain information regarding urinary incontinence or fecal leakage, which are well-known side effects particularly after EBRT and are better assessed in quality-of-life studies. Lymphadenectomy was heterogeneously performed. Finally, we believe that RT and chemotherapy should be considered for patients with locally advanced disease and those with clear-cell or serous-papillary histology on the basis of the high frequency of distant recurrence and LRR observed. $^{24-27}$ The role of chemotherapy in stage I-II disease with high-risk pathologic features is under evaluation in the ongoing PORTEC-3 trial.

\section{CONCLUSION}

For patients with high- or intermediate-risk EC, VB alone offers high rates of local control with no severe complications. EBRT should be tailored to patients with high-risk features because the possible severe late toxicity may outweigh the benefits. The addition of a VB boost after EBRT is associated with higher-than-expected late severe complications. The correlation between severe late toxicity and RT techniques is observed in our study. When EBRT is indicated, IMRT and daily image-guided RT should be considered as a viable treatment option to minimize severe late toxicity. Patients should be informed about the potential increased risk of second malignancies after the diagnosis of EC and PORT because 2D-EBRT techniques significantly increase the risk of second tumors and the severity of side effects. Longer follow-up and more patients are needed to confirm the lowest second cancer rates obtained with IMRT in this study. The potential benefits observed with IMRT should be confirmed in a randomized trial.

ACKNOWLEDGMENT The authors are grateful to Julia Rengiers for her excellent help in the preparation of the manuscript.

CONFLICT OF INTEREST Authors declared no conflicts of interest.

\section{REFERENCES}

1. Ferlay J, Shin HR, Bray F, Forman D, Mathers C, Parkin DM. Estimates of worldwide burden of cancer in 2008: GLOBOCAN 2008. Int J Cancer. 2010;127:2893-917.

2. Ferlay J, Parkin DM, Steliarova-Foucher E. Estimates of cancer incidence and mortality in Europe in 2008. Eur J Cancer. 2010;46:765-81.

3. Keys HM, Roberts JA, Brunetto VL, Zaino RJ, Spirtos NM, Bloss JD, et al. A phase III trial of surgery with or without adjunctive external pelvic radiation therapy in intermediate risk endometrial adenocarcinoma: a gynecologic oncology group study. Gynecol Oncol. 2004;92:744-51.

4. Aalders J, Abeler V, Kolstad P, Onsrud M. Postoperative external irradiation and prognostic parameters in stage I endometrial carcinoma: clinical and histopathologic study of 540 patients. Obstet Gynecol. 1980;56:419-27.

5. Creutzberg CL, van Putten WL, Koper PC, Lybeert ML, Jobsen JJ, Wárlám-Rodenhuis CC, et al. Surgery and postoperative radiotherapy versus surgery alone for patients with stage-1 endometrial carcinoma: multicentre randomised trial. PORTEC study group. Post operative radiation therapy in endometrial carcinoma. Lancet. 2000;355(9213):1404-11.

6. Group AES, Blake P, Swart AM, Orton J, Kitchener H, Whelan $\mathrm{T}$, et al. Adjuvant external beam radiotherapy in the treatment of 
endometrial cancer (MRC ASTEC and NCIC CTG EN.5 randomised trials): pooled trial results, systematic review, and metaanalysis. Lancet. 2009;373(9658):137-46.

7. Sorbe B, Horvath G, Andersson H, Boman K, Lundgren C, Pettersson B. External pelvic and vaginal irradiation versus vaginal irradiation alone as postoperative therapy in medium-risk endometrial carcinoma: a prospective randomized study. Int $J$ Radiat Oncol Biol Phys. 2012;82:1249-55.

8. Kong A, Johnson N, Kitchener HC, Lawrie TA. Adjuvant radiotherapy for stage I endometrial cancer: an updated Cochrane systematic review and meta-analysis. J Natl Cancer Inst. 2012; 104:1625-34.

9. Creutzberg CL, van Putten WL, Koper PC, Lybeert ML, Jobsen JJ, Wárlám-Rodenhuis CC, et al. The morbidity of treatment for patients with stage I endometrial cancer: results from a randomized trial. Int J Radiat Oncol Biol Phys. 2001;51:1246-55.

10. Nout RA, Smit VT, Putter H, Jürgenliemk-Schulz IM, Jobsen JJ, Lutgens LC, et al. Vaginal brachytherapy versus pelvic external beam radiotherapy for patients with endometrial cancer of highintermediate risk (PORTEC-2): an open-label, non-inferiority, randomised trial. Lancet. 2010;375(9717):816-23.

11. Onsrud M, Cvancarova M, Hellebust TP, Trope CG, Kristensen GB, Lindemann K. Long-term outcomes after pelvic radiation for early-stage endometrial cancer. J Clin Oncol. 2013;31:3951-6.

12. Zwahlen DR, Ruben JD, Jones P, Gagliardi F, Millar JL, Schneider U. Effect of intensity-modulated pelvic radiotherapy on second cancer risk in the postoperative treatment of endometrial and cervical cancer. Int J Radiat Oncol Biol Phys. 2009;74:539-45.

13. Morrow CP, Bundy BN, Kurman RJ, Creasman WT, Heller P, Homesley HD, et al. Relationship between surgical-pathological risk factors and outcome in clinical stage I and II carcinoma of the endometrium: a gynecologic oncology group study. Gynecol Oncol. 1991;40:55-65.

14. Small W Jr, Mell LK, Anderson P, Creutzberg C, De Los Santos $\mathrm{J}$, Gaffney D, et al. Consensus guidelines for delineation of clinical target volume for intensity-modulated pelvic radiotherapy in postoperative treatment of endometrial and cervical cancer. Int J Radiat Oncol Biol Phys. 2008;71:428-34.

15. Creutzberg CL, Nout RA, Lybeert ML, Wárlám-Rodenhuis CC, Jobsen JJ, Mens JW, et al. Fifteen-year radiotherapy outcomes of the randomized PORTEC-1 trial for endometrial carcinoma. Int J Radiat Oncol Biol Phys. 2011;81:e631-8.

16. Klopp AH, Jhingran A, Ramondetta L, Lu K, Gershenson DM, Eifel PJ. Node-positive adenocarcinoma of the endometrium: outcome and patterns of recurrence with and without external beam irradiation. Gynecol Oncol. 2009;115:6-11.

17. Nout RA, Putter H, Jurgenliemk-Schulz IM, Jobsen JJ, Lutgens LC, van der Steen-Banasik EM, et al. Five-year quality of life of endometrial cancer patients treated in the randomised post operative radiation therapy in endometrial cancer (PORTEC-2) trial and comparison with norm data. Eur J Cancer. 2012;48: $1638-48$

18. Irwin C, Levin W, Fyles A, Pintilie M, Manchul L, Kirkbride P. The role of adjuvant radiotherapy in carcinoma of the endometrium: results in 550 patients with pathologic stage I disease. Gynecol Oncol. 1998;70:247-54.

19. Crosby MA, Tward JD, Szabo A, Lee CM, Gaffney DK. Does brachytherapy improve survival in addition to external beam radiation therapy in patients with high risk stage I and II endometrial carcinoma? Am J Clin Oncol. 2010;33:364-9.

20. Kidd EA, Siegel BA, Dehdashti F, Rader JS, Mutic S, Mutch DG, et al. Clinical outcomes of definitive intensity-modulated radiation therapy with fluorodeoxyglucose-positron emission tomography simulation in patients with locally advanced cervical cancer. Int J Radiat Oncol Biol Phys. 2010;77:1085-91.

21. Wright JD, Deutsch I, Wilde ET, Ananth CV, Neugut AI, Lewin $\mathrm{SN}$, et al. Uptake and outcomes of intensity-modulated radiation therapy for uterine cancer. Gynecol Oncol. 2013;130:43-8.

22. Jhingran A, Winter K, Portelance L, Miller B, Salehpour M, Gaur $\mathrm{R}$, et al. A phase II study of intensity modulated radiation therapy to the pelvis for postoperative patients with endometrial carcinoma: radiation therapy oncology group trial 0418. Int J Radiat Oncol Biol Phys. 2012;84:e23-8.

23. Chaturvedi AK, Engels EA, Gilbert ES, Chen BE, Storm H, Lynch CF, et al. Second cancers among 104,760 survivors of cervical cancer: evaluation of long-term risk. J Natl Cancer Inst. 2007;99:1634-43.

24. Randall ME, Filiaci VL, Muss H, Spirtos NM, Mannel RS, Fowler J, et al. Randomized phase III trial of whole-abdominal irradiation versus doxorubicin and cisplatin chemotherapy in advanced endometrial carcinoma: a gynecologic oncology group study. J Clin Oncol. 2006;24:36-44.

25. Maggi R, Lissoni A, Spina F, Melpignano M, Zola P, Favalli G, et al. Adjuvant chemotherapy vs radiotherapy in high-risk endometrial carcinoma: results of a randomised trial. $\mathrm{Br} J$ Cancer. 2006;95:266-71.

26. Susumu N, Sagae S, Udagawa Y, Niwa K, Kuramoto H, Satoh S, et al. Randomized phase III trial of pelvic radiotherapy versus cisplatin-based combined chemotherapy in patients with intermediate- and high-risk endometrial cancer: a Japanese gynecologic oncology group study. Gynecol Oncol. 2008;108: 226-33.

27. Boruta DM II, Gehrig PA, Fader AN, Olawaiye AB. Management of women with uterine papillary serous cancer: a society of gynecologic oncology (SGO) review. Gynecol Oncol. 2009; 115:142-53. 